\title{
Resposta do jiggs à adubação nitrogenada e alturas de corte
}

\author{
Marcieli Maccari, Sidinei Peretti, Vanessa Soriano, Vitor Castioni, Jonas Guerra
}

Universidade do Oeste de Santa Catarina - UNOESC, Xanxerê, SC. E-mail: marcieli.maccari@unoesc.edu.br

\begin{abstract}
Resumo
O alto valor nutritivo e a grande flexibilidade de uso tem estimulado o cultivo do Jiggs (Cynodon spp.) tanto em clima tropical como em subtropical. A produção, as características bromatológicas e morfológicas da forrageira são afetadas pela altura de corte e adubação nitrogenada adotadas no manejo do Jiggs. 0 objetivo deste estudo foi avaliar o efeito de doses de nitrogênio $\left(0,50,100,150,200\right.$ e $250 \mathrm{~kg}$ de $\mathrm{N} \mathrm{ha}^{-1}$ ) e duas alturas de corte $(0$ e $7 \mathrm{~cm}$ ) no comportamento produtivo e qualitativo da forragem de Jiggs em regime de corte. $O$ delineamento experimental foi inteiramente casualizado em parcelas subdivididas, com 3 repetições. As doses nitrogenadas foram alocadas na parcela principal e a altura de corte na parcela secundária. As variáveis analisadas foram: produção total de matéria seca (MS), taxa de acúmulo de MS, composição estrutural da forragem (folhas, colmos e material morto), teor de proteína bruta (PB). A adubação nitrogenada em cobertura e a altura de corte a $7 \mathrm{~cm}$ incrementou a produção total de MS, taxa de acúmulo e a quantidade de folhas verdes na forragem. A produção total de MS e a taxa de acúmulo se adequaram ao modelo de regressão quadrático, enquanto que a quantidade de folhas e colmos ao modelo linear crescente e de material morto foram ajustados ao modelo linear decrescente com a inclusão de doses de adubação nitrogenada. Independente da altura de corte, a aplicação de $\mathrm{N}$ em cobertura aumentou de forma linear crescente os teores de PB. O fornecimento de nitrogênio em cobertura e o manejo a $7 \mathrm{~cm}$ de altura é indicado a fim aumentar a produção de MS, taxa de acúmulo de MS, produção de folhas e teor de proteína bruta da forragem de Jiggs, aumentando assim a sua eficiência forrageira.
\end{abstract}

Palavras-chave: Cynodon spp.; eficiência forrageira; produção forrageira.

\section{Response of jiggs to nitrogen fertilization and cutting height}

\begin{abstract}
The nutritional value and great flexibility of use has stimulated the cultivation of Jiggs (Cynodon spp.) in tropical and subtropical climates. The production, the bromatological and morphological characteristics of the forage are affected decisively by the cutting height and nitrogen fertilization adopted in the management of the Jiggs. The goal of this study was to evaluate the effect of nitrogen rates $(0,50,100$, 150,200 and $250 \mathrm{~kg}$ of $\left.\mathrm{N} \mathrm{ha}^{-1}\right)$ and two cutting heights $(0$ and $7 \mathrm{~cm}$ ) on productive and qualitative performance of Jiggs on cutting regime. The experimental design was completely randomized in subdivided plots, with 3 replicates. The nitrogen rates were allocated in the main plot and the cutting height in the secondary plot. The variables analyzed were: total DM production, DM accumulation rate, forage structural composition (leaves, stems and dead material), and crude protein content. Nitrogen fertilization on cover and cutting height at $7 \mathrm{~cm}$ increased the total DM production, accumulation DM rate and the number of leaves in the forage. The total DM production and the accumulation DM rate were adjusted to the quadratic regression model, while the number of leaves and stems were adjusted to the linear model increasing and of dead material to the linear model decreasing with the inclusion of doses of nitrogen fertilization. Regardless of the cutting height, the application of $\mathrm{N}$ in coating increased linearly the crude protein levels in forage. The supply of nitrogen under cover and management at $7 \mathrm{~cm}$ height is indicated in order to increase DM production, DM accumulation rate, leaf yield and crude protein content of Jiggs forage, thus increasing its forage efficiency.
\end{abstract}

Keywords: Cynodon spp.; forage efficiency; forage production. 


\section{Introdução}

O gênero Cynodon é amplamente utilizado na produção animal como forrageira para corte, feno ou pastejo. A elevada produção, a boa adaptabilidade, o alto valor nutritivo e a grande flexibilidade de uso tem estimulado o cultivo do Jiggs (FAGUNDES et al., 2011) tanto em clima tropical como em subtropical.

Entretanto, a quantidade e a qualidade de informações disponíveis sobre o comportamento produtivo e o manejo do Jiggs são insuficientes. Para obtenção do máximo potencial desta forrageira é fundamental compreender a sua resposta produtiva e qualitativa frente ao manejo adotado. A produção, as características bromatológicas e morfológicas são afetadas decisivamente pela altura de corte e adubação nitrogenada (REZENDE et al., 2015) adotadas no manejo da forrageira.

O fornecimento de nitrogênio proporciona incrementos na produção de matéria seca e altera a composição bromatológica (VITOR et al., 2009; VIANA et al., 2011; REZENDE et al., 2015), pois o nitrogênio é o principal integrante das proteínas, enzimas, fitocromos, coenzimas, ácidos nucleicos (DNA e RNA), bases nitrogenadas e também faz parte da clorofila e fito-hormônios. Assim, a utilização de adubação nitrogenada torna-se uma estratégia para intensificar a produção de massa seca e melhorar a sua qualidade bromatológica (REZENDE et al., 2015). Por outro lado, a deficiência de nitrogênio pode desencadear o processo de senescência das plantas e subestimar o potencial produtivo da espécie (VIANA et al., 2011).

As mudanças causadas pela adubação nitrogenada no crescimento da planta geram a necessidade de ajustes na altura de corte a fim de garantir a eficiência de colheita da forragem e produzir uma forragem de maior qualidade (FONSECA et al., 2008). A recuperação de uma forrageira após a desfolha, por corte ou pastejo, é influenciada por suas características morfológicas intrínsecas, que são a área foliar remanescente, os teores de carboidratos não estruturais de reserva, bem como pelo número de pontos de crescimento capazes de promover a rebrota (PEDREIRA et al., 2001).

O corte para a produção de feno ou para o fornecimento de forragem fresca para os animais, geralmente é realizado rente ao solo. Entretanto, esta prática favorece o processo de erosão do solo como também pode estar subestimando a capacidade produtiva da espécie. Ao utilizar altura de corte a $7 \mathrm{~cm}$, Silva et al. (2015) verificaram que o Jiggs, Tifton 85 e o Vaqueiro, responderam positivamente ao regime de cortes, aumentando o potencial produtivo de forragem. $\mathrm{Na}$ literatura são inúmeros os trabalhos que estudam a resposta forrageira a adubação nitrogenada, mas são escassos os trabalhos que além deste fator, estudam o manejo da altura de corte a fim de maximizar a produção e a qualidade forrageira.

O objetivo desta pesquisa foi avaliar a capacidade produtiva e qualitativa da forragem de Jiggs submetida a doses de adubação nitrogenada e alturas de corte.

\section{Material e Métodos}

O estudo foi realizado na área experimental da Universidade do Oeste de Santa Catarina -Unoesc, no município de Xanxerê-SC a $26^{\circ} 52^{\prime} 24,63^{\prime \prime} S$ e $52^{\circ} 25^{\prime} 16,64^{\prime \prime O}$, com altitude de $842 \mathrm{~m}$. O solo da área é classificado como um Latossolo Vermelho distrófico (EMBRAPA, 2013) e - clima da região é $\mathrm{Cfb}$, subtropical úmido (ALVARES et al., 2014).

$O$ experimento foi alocado num delineamento experimental inteiramente casualizado em esquema de parcelas subdivididas com 3 repetições. As parcelas experimentais possuíam dimensões de $2 \times 3 \mathrm{~m}$ totalizando $6 \mathrm{~m}^{2}$ cada. A dose nitrogenada compôs a parcela principal, sendo alocada a altura de corte na parcela secundária. Foram avaliadas seis doses de adubação nitrogenada $(0,50,100,150,200$ e 250 $\mathrm{kg}$ de $\mathrm{N} \mathrm{ha}^{-1}$ ) e duas alturas de corte $(0$ e $7 \mathrm{~cm})$.

As amostras de solo foram coletadas na profundidade de $0-20 \mathrm{~cm}$ e enviadas ao laboratório de solos da Unoesc, para verificação das condições químicas do solo da área experimental. Segundo os resultados da análise de solo, o histórico da cultura anterior e as exigências da espécie a ser implantada, mostraram que a área não necessitava de correção das suas condições químicas (Tabela 1 ) conforme (CQFS, 2016). 
Tabela 1. Resultados da análise de solo na profundidade $0-20 \mathrm{~cm}$ proveniente da área experimental para implantação do Jiggs. Xanxerê-SC, 2013.

\begin{tabular}{ccccccccccc}
\hline Argila & $\mathrm{pH}-\mathrm{H}_{2} \mathrm{O}$ & Índice & $\mathrm{P}$ & $\mathrm{K}$ & $\mathrm{MO}$ & $\mathrm{Al}$ & $\mathrm{Ca}$ & $\mathrm{Mg}$ & $\mathrm{H}+\mathrm{Al}$ & $\mathrm{CTC}$ \\
\hline$\%$ & & $\mathrm{SMP}$ & $-\left(\mathrm{mg} \mathrm{dm}^{-3}\right)-$ & $\%$ & & $---------------\left(\mathrm{cmolc} \mathrm{dm}^{-3}\right)$------------- \\
\hline 62 & 5,64 & 5,96 & 10 & 82,84 & 2,7 & 0,1 & 6,36 & 4,56 & 15,33 & 68,88 \\
\hline
\end{tabular}

P: fósforo; K: potássio; M.O.: matéria orgânica; Al: Alumínio; Ca: cálcio; Mg: magnésio; H: hidrogênio; CTC: capacidade de troca de cátions.

A implantação da cultura ocorreu no verão 2013/2014, na segunda quinzena de outubro, com uso de mudas propagadas em bandejas de isopor em sistema de cultivo protegido para facilitar o manejo de implantação no campo experimental.

As mudas foram obtidas a partir do enraizamento de estacas em bandejas de isopor com 200 células. O substrato utilizado nas bandejas foi composto por vermiculita expandida, casca de pinus e casca de arroz carbonizada. O plantio das estacas ocorreu em abril de 2013 e as bandejas com as mudas foram mantidas em estufa, onde receberam irrigações diárias de acordo com a necessidade das plantas. Em outubro de 2013, as mudas foram levadas a campo onde utilizou-se o espaçamento de $30 \mathrm{~cm}$ entre linhas e entre plantas dentro da linha para a implantação das unidades experimentais no campo. As condições ambientais para o período de estabelecimento das mudas no campo e o seu desenvolvimento foram adequadas. Na figura 1 são apresentados os dados climáticos registrados durante o período experimental.

Figura 1. Precipitação $(\mathrm{mm})$, temperatura mínima, média e máxima em graus Celsius observadas durante o período de desenvolvimento da pesquisa, dados climáticos coletados na Estação Meteorológica da Unoesc - Xanxerê, no período de outubro de 2013 a abril de 2014.

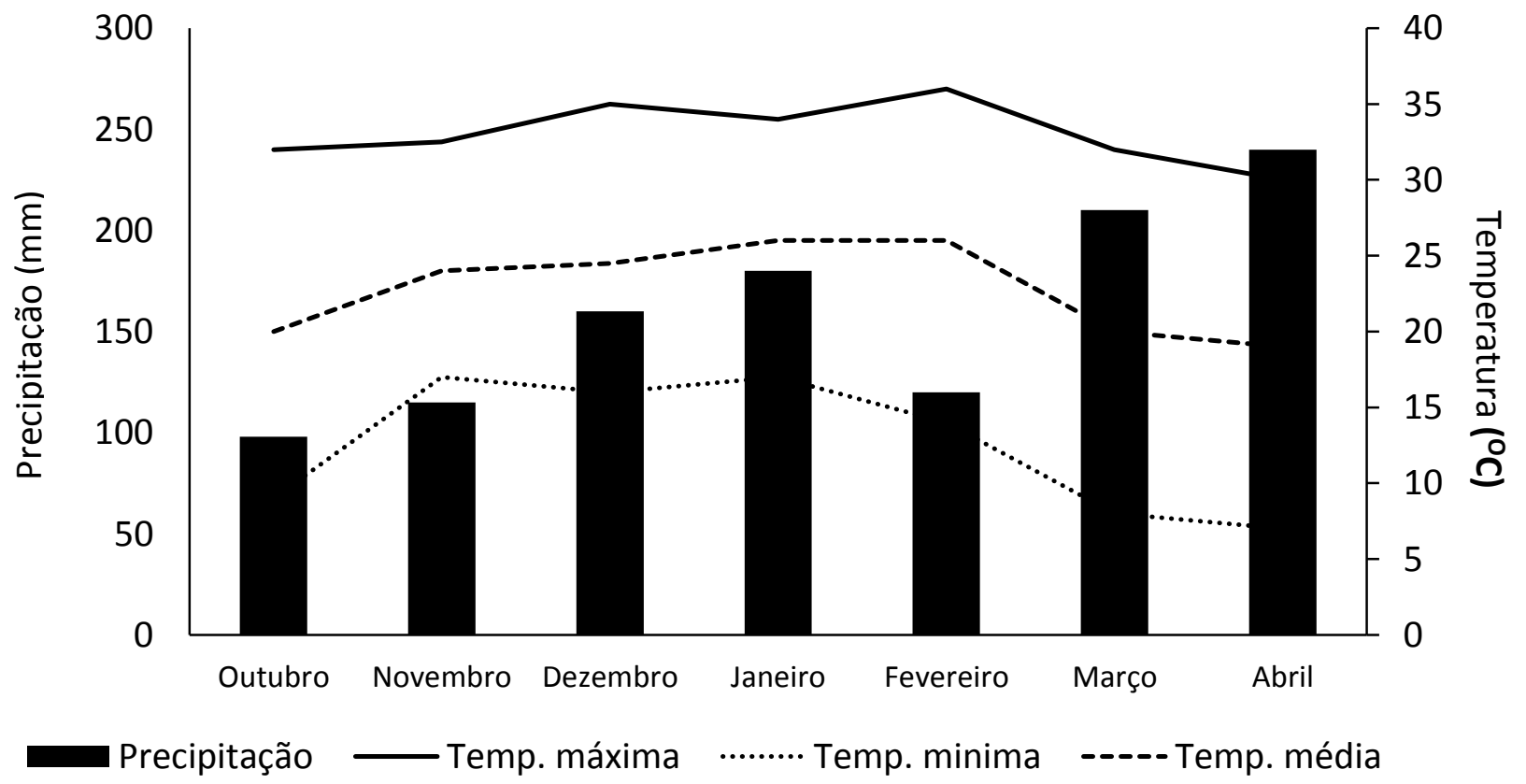

A avaliação da forrageira foi realizada entre o período de 04 de fevereiro a 24 de abril de 2014, totalizando 79 dias. No dia 04/02/2014 foi realizado o corte de nivelamento de acordo com a altura pretendida, ou seja, a 0 ou a $7 \mathrm{~cm}$ em todas as unidades experimentais. Após o corte de nivelamento em todas as parcelas foi realizada a primeira aplicação da adubação 
nitrogenada usando como fonte nitrogenada, a ureia ( $45 \%$ de N). A quantidade de ureia aplicada em cada parcela experimental correspondeu a cada dose avaliada, sendo a dose total dividida em duas aplicações, a primeira realizada no dia $09 / 02 / 2014$ e a segunda no dia 05/03/2014. As condições de umidade estavam adequadas para a aplicação de ureia nas unidades experimentais.

A altura das plantas foi tomada ao nível do solo até a curvatura da folha mais alta sem comprimi-la. Foram realizados cortes nas seguintes datas: 05 de março; 22 de março; 5 de abril e 24 de abril para ambas as alturas de corte. Duas amostras de forragem foram coletadas em cada parcela, ao final de cada ciclo de crescimento sempre que o dossel atingia em média $20 \mathrm{~cm}$ de altura tanto para a altura $0 \mathrm{~cm}$ (rente ao solo) como para a altura $7 \mathrm{~cm}$. 0 monitoramento da altura da pastagem nas unidades experimentais era realizado a cada 3 dias com auxílio de um bastão graduado em centímetros (sward stick).

Para delimitar a área a ser cortada foi utilizado um quadro metálico de $0,5 \times 0,5 \mathrm{~m}(0,25$ $\mathrm{m}^{2}$ ). Os cortes foram realizados com o auxilio de uma tesoura de esquila de acordo com a altura desejada (0 ou $7 \mathrm{~cm}$ ). A forragem proveniente destas amostras foi homogeneizada, sendo retiradas duas amostras compostas. Uma amostra foi pesada e levada para estufa de ventilação forçada de ar a $55^{\circ} \mathrm{C}$ até peso constante para determinação do teor de matéria seca (MS). Após secas e pesadas foram trituradas em moinho estacionário tipo "Willey" utilizandose peneira com malha de $1 \mathrm{~mm}$ de abertura para determinação da composição química da forragem. Os teores de matéria seca (MS) e nitrogênio $(\mathrm{N})$ foram determinados seguindo os métodos descritos pela AOAC (1990). Sendo calculado o teor de proteína bruta (PB) por meio da multiplicação entre o teor de nitrogênio por 6,25 (\% PB = \% N X 6,25).

A outra amostra foi utilizada para a avaliação da composição morfológica da forragem, sendo separadas em: folha, colmo e material morto. Após a separação cada componente foi pesado e levado à estufa de ventilação forçada de ar a $55^{\circ} \mathrm{C}$ até peso constante. A partir destas informações foram estimados os percentuais de folha, colmo e material morto com base da massa total de forragem produzida.

A produção de MS em cada corte foi calculada pelo somatório das massas de folhas, colmos e material morto, extrapolando a massa obtida no corte da massa original do quadrado para um hectare. Somando-se a produção de MS de cada corte calculou-se a produção total de MS em kg ha-1.

A taxa de acúmulo de MS em kg ha ${ }^{-1} \mathrm{dia}^{-1}$, foi calculada a partir da massa de forragem de cada período, dividindo essa pela duração do ciclo em dias de cada corte, obtendo assim a quantidade de massa de forragem produzida por dia no ciclo. Após o corte de cada parcela, com auxílio de roçadeira mecanizada era realizado o nivelamento de toda a parcela experimental de acordo com alocação dos tratamentos.

Os dados foram submetidos a análise da variância pelo teste $F$ usando o software Statgraphics. Quando os dados quantitativos tiveram efeito significativo, conforme a análise de variância, os dados de produção de MS, taxa de acúmulo e teor de proteína bruta foram submetidos à análise de regressão polinomial. As médias da composição botânica da forragem foram comparadas pelo teste de Tukey a $5 \%$ de significância.

Para o estudo do comportamento da taxa de acúmulo de MS e produção total de MS (y) sob utilização de doses de adubação nitrogenada, utilizou-se o modelo polinomial de segundo grau:

$$
y=\beta_{1}+\beta_{2} x+\beta_{3} x^{2}(1)
$$

em que $\beta_{1}$ : intercepto; $\beta_{2}$ : é a taxa de variação na origem; $\beta_{3}$ : mede $\mathrm{o}$ grau de curvatura $\mathrm{e}$ orientação da concavidade da parábola. Dado o interesse pelo ponto crítico $x_{m}$ e $o$ valor correspondente da função $y_{m}$, utilizou-se o modelo polinomial reparametrizado por Zeviani (2013) para tê-los como parâmetros do modelo, ajustando-se

$$
y=y_{m}+c\left(x+x_{m}\right)^{2}(2)
$$

em que $y_{m}$ : valor máximo (taxa de acúmulo de MS e produção total); c: parâmetro sem interpretação que controla a forma da curva; $x_{m}$ : valor de $x$ para o máximo da função (dose nitrogenada em que estima a máxima taxa de acúmulo de MS, produção total de MS e teor de proteína bruta).

\section{Resultados e Discussão}

Foi observada interação significativa $(P<0,05)$ para doses de $\mathrm{N}$ e alturas de corte para a produção de MS da forragem, taxa de acúmulo de matéria seca (MS) e para o teor de Proteína Bruta (PB).

Independente da altura de corte, foi observado aumento da produção de MS quando 
utilizado o nitrogênio em cobertura. Para ambas as alturas de corte, os dados se ajustaram ao modelo quadrático de regressão. As equações para os dados de produção total de MS rente ao solo foram: $Y=-0,056 X^{2}+20,618 X+3.467,9$ e para a altura a $7 \mathrm{~cm}$ foi $Y=-0,0723 X^{2}+33,782 X+$ $2.985,6$. Na figura 2, são apresentadas as curvas de produção total de matéria seca em função das doses de $\mathrm{N}$ e alturas de corte. Nessas equações, considera-se $Y$ a estimativa da produção de $M S$, expressa em kg de $\mathrm{MS} \mathrm{ha}^{-1}$, e $\mathrm{X}$ a dose de $\mathrm{N}$, expressa em $\mathrm{kg}$ de $\mathrm{Nha}^{-1}$.

Figura 2. Produção total de $\mathrm{MS}$ em $\mathrm{kg} \mathrm{MS} \mathrm{ha}^{-1}$ de acordo com as doses de adubação nitrogenada e altura de corte da forragem de Jiggs.

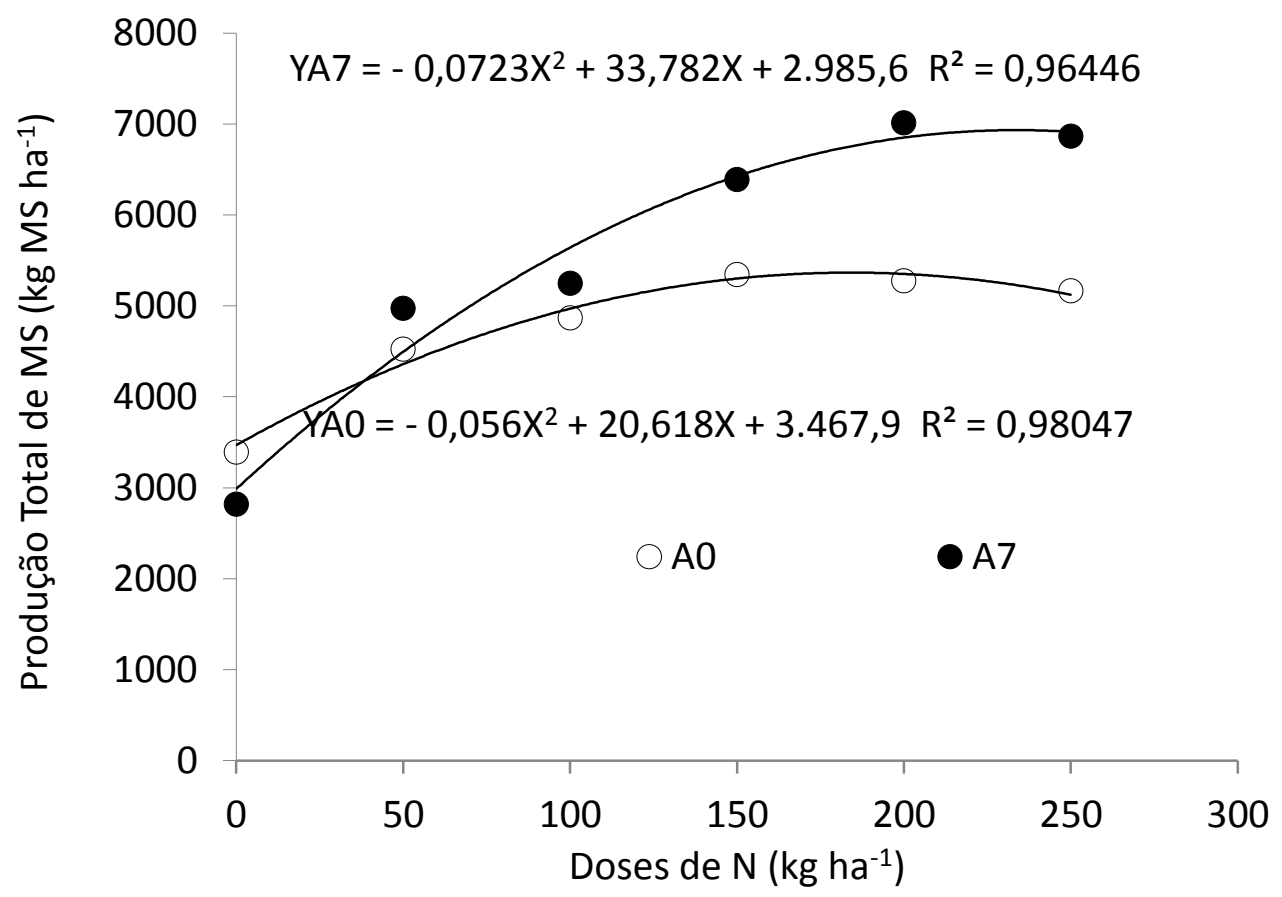

A0: Altura de corte a $0 \mathrm{~cm}$ ou rente ao solo; A7: Altura de corte a $7 \mathrm{~cm}$.

Quando não foi utilizada a adubação nitrogenada em cobertura foi obtida produção de MS de $3.394 \mathrm{~kg} \mathrm{ha}^{-1}$ para a forragem cortada rente ao solo. Já quando a forrageira foi manejada a $7 \mathrm{~cm}$ de altura a produção de $\mathrm{MS}$ observada foi de $2.819 \mathrm{~kg} \mathrm{ha}^{-1}$. A menor produção de MS, no corte a $7 \mathrm{~cm}$ de altura sem a utilização de $\mathrm{N}$ em cobertura, pode estar associada a redução da disponibilidade de $\mathrm{N}$ na matéria orgânica do solo pela ação microbiana. Já no corte a $0 \mathrm{~cm}$, a ação microbiana foi suprimida e provavelmente houve a disponibilização do $\mathrm{N}$ da matéria orgânica do solo para a forrageira.

Ao fornecer $\mathrm{N}$ em cobertura para a forrageira, a reposta produtiva foi alterada, sendo possível observar superioridade na produção de MS quando o Jiggs foi manejado a 7 $\mathrm{cm}$ de altura. Assim como nesta pesquisa em sistema de corte, Roecker et al. (2011) e Dore
(2006), verificaram incremento produtivo com a utilização de adubação nitrogenada em Jiggs. Roecker et al. (2011) obtiveram produção de $5.604 \mathrm{~kg}$ de $\mathrm{MS} \mathrm{ha}^{-1}$ com a utilização de $300 \mathrm{~kg}$ de $\mathrm{N}$ ha ${ }^{-1}$ e Dore (2006) obteve produção de MS de $8.629 \mathrm{~kg}$ de $\mathrm{MS} \mathrm{ha}^{-1}$ quando foram utilizados 112 $\mathrm{kg}$ de $\mathrm{N} \mathrm{ha}{ }^{-1}$ em 42 dias de utilização do Jiggs.

As estimativas da produção total de MS máxima para o corte a 0 e $7 \mathrm{~cm}$ de altura foram determinadas de acordo com o modelo polinomial reparametrizado por Zeviani (2013), sendo obtidos os valores de 5.221,74 a 5.510,38 $\mathrm{kg}$ de $\mathrm{MS} \mathrm{ha}^{-1}$ ao utilizar doses de $163,03 \mathrm{~kg} \mathrm{~N} \mathrm{ha}^{-1}$ a $205,2 \mathrm{~kg}$ de $\mathrm{N} \mathrm{ha}^{-1}$ e para o corte a $7 \mathrm{~cm}$ de altura foi de $6.387,86$ a $7.479,18 \mathrm{~kg}$ de $\mathrm{MS} \mathrm{ha}^{-1}$ com doses de 155,48 a $311,98 \mathrm{~kg} \mathrm{~N} \mathrm{ha}^{-1}$ com intervalo de confiança de $95 \%$. Considerando o limite máximo inferior da produção de MS e o limite máximo inferior da adubação nitrogenada, 
verifica-se incremento na produção de $\mathrm{MS}$ na ordem de 22,33\% e redução de 4,63\% da aplicação de $\mathrm{N}$ ao elevar o corte a $7 \mathrm{~cm}$ de altura.

O nitrogênio é um macronutriente essencial às plantas e o mais requerido quantitativamente para o seu desenvolvimento, assim quanto maior a produção de MS maior será a necessidade de $\mathrm{N}$ pela cultura. Dessa forma, no manejo da forragem a $7 \mathrm{~cm}$ de altura ocorre maior necessidade de $\mathrm{N}$ para atender a demanda deste elemento durante o crescimento da forrageira.

A utilização de $\mathrm{N}$ nos sistemas produtivos é muito discutida, pois a prática envolve além de custos elevados, riscos ambientais, porque o nutriente está sujeito a perdas por lixiviação, desnitrificação e volatilização (AMADO et al. 2002). Por isso, é importante que a quantidade de $\mathrm{N}$ aplicada às forrageiras seja a mais exata possível, minimizando os excessos que prejudicam a qualidade ambiental e oneram o produtor.

Para a taxa de acúmulo de MS em kg de MS ha-1 dia ${ }^{-1}$ foi observada interação significativa entre doses de $\mathrm{N}$ e alturas de corte $(\mathrm{P}<0,05)$ e da mesma forma que a produção de MS, observa-se que ocorreu aumento da taxa de acúmulo quando utilizado nitrogênio em cobertura, independente da altura de corte (Figura 3).

$\mathrm{Na}$ altura de corte a $0 \mathrm{~cm}$ do solo, a taxa de acúmulo variou de 35,7 a 86,9 kg de $\mathrm{MS} \mathrm{ha}^{-1}$ dia $^{-1}$ e na altura a $7 \mathrm{~cm}$ houve variação de 43 a $65,4 \mathrm{~kg}$ de MS ha ${ }^{-1}$ dia $^{-1}$ de acordo com as doses crescentes de $\mathrm{N}(0,50,100,150,200$ e $250 \mathrm{~kg}$ de $\mathrm{N} \mathrm{ha}{ }^{-1}$ ). Para ambas alturas de corte houve ajuste ao modelo quadrático de equação.

Na ausência da adubação nitrogenada, a maior taxa de acúmulo de MS quando a pastagem foi cortada a $0 \mathrm{~cm}$ de altura pode ter sido explicada pela maior interceptação luminosa, considerando o hábito de crescimento desta pastagem. A partir do fornecimento de 50 kg de $\mathrm{N} \mathrm{ha}^{-1}$ a taxa de acúmulo de $\mathrm{MS}$ passou a ser superior na altura de corte a $7 \mathrm{~cm}$ para todas as doses avaliadas.

A taxa de acúmulo de MS máxima foi estimada na ordem de 66,1 a 69,75 kg de MS ha ${ }^{1} \mathrm{dia}^{-1}$ para o corte rente ao solo ao utilizar doses de $163 \mathrm{~kg} \mathrm{~N} \mathrm{ha}^{-1}$ a 205,2 $\mathrm{kg}$ de $\mathrm{N} \mathrm{ha}^{-1}$ e para o corte a $7 \mathrm{~cm}$ de altura foi de 80,86 a 94,66 kg de MS ha ${ }^{-1}$ dia $^{-1}$ com doses de 155,48 a $311,98 \mathrm{~kg} \mathrm{~N}$ $\mathrm{ha}^{-1}$ com intervalo de confiança de 95\%, conforme modelo polinomial reparametrizado por Zeviani (2013).

Figura 3. Taxa de acúmulo de $\mathrm{MS}\left(\mathrm{kg} \mathrm{ha}^{-1} \mathrm{dia}^{-1}\right)$ de acordo com doses de adubação nitrogenada e alturas de corte da pastagem de Jiggs.

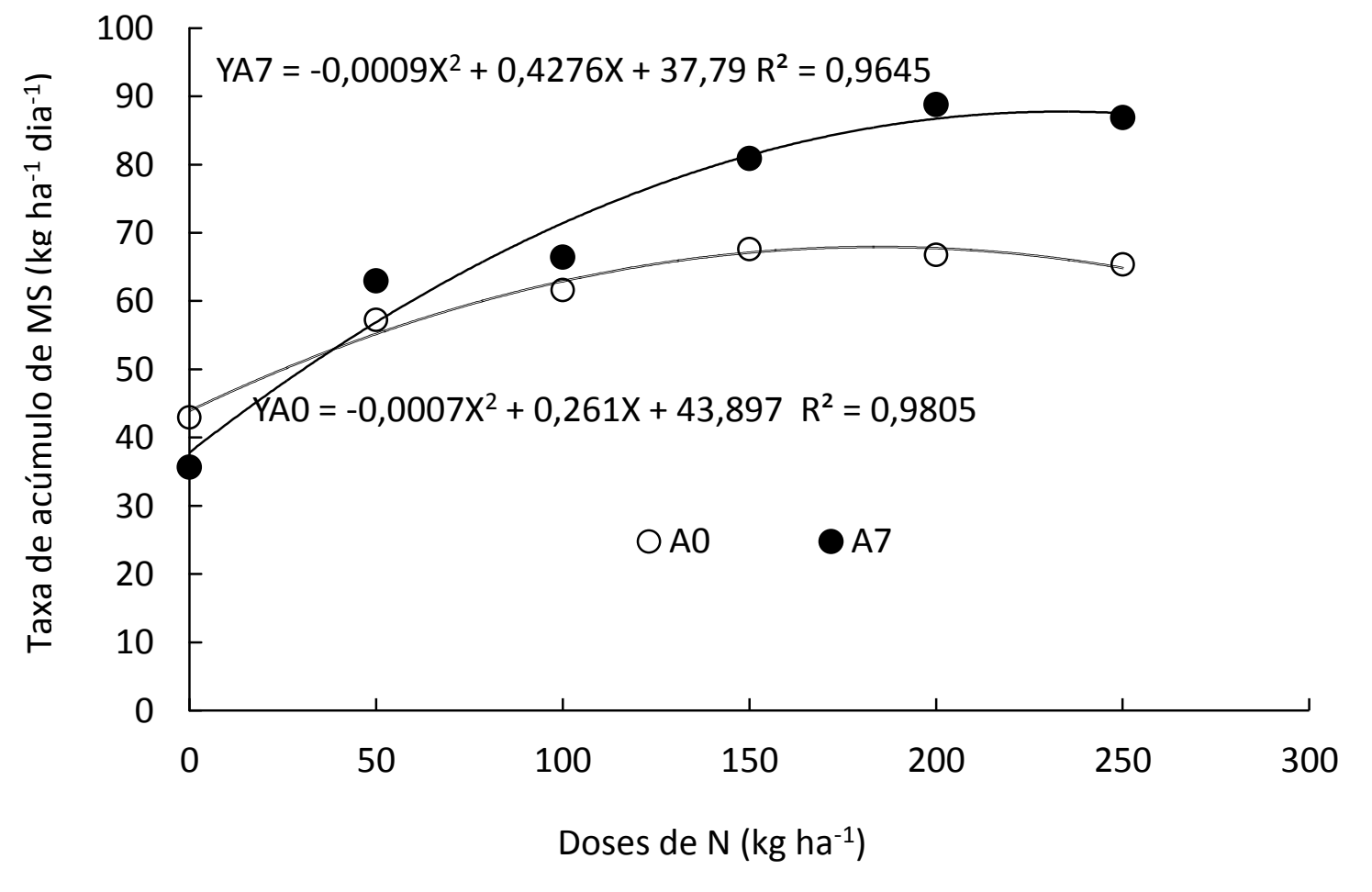

A0: Altura de corte a $0 \mathrm{~cm}$ ou rente ao solo; A7: Altura de corte a $7 \mathrm{~cm}$. 
Os dados obtidos nesta pesquisa quanto a taxa de acúmulo de $\mathrm{MS} \mathrm{ha}^{-1}$ dia $^{-1}$ são similares aos relatados na literatura para Cynodon cv. Tifton 85, de 24,5 a $104,3 \mathrm{~kg} \mathrm{ha}^{-1} \mathrm{dia}^{-1}$ de MS (CARNEVALLI; SILVA 1999). Fagundes et al. (2005), obtiveram incremento na taxa de acúmulo de MS com a aplicação de doses de até $400 \mathrm{~kg}$ de $\mathrm{N} \mathrm{ha}^{-1}$ em Tifton 85. Parsons et al. (1983), verificaram que a taxa de acúmulo está relacionada ao índice de área foliar, ou seja, ocorre maior taxa de acúmulo quando as folhas jovens ficam expostas a altas intensidades luminosas aumentando o seu potencial fotossintético.

Segundo Silva et al. (2011), após o corte da forrageira, começa o processo de rebrota com o objetivo de refazer a área foliar, interceptar luz e crescer novamente. No início do processo de rebrote são produzidas principalmente folhas, sendo o acúmulo de colmos e de material morto muito pequeno. Para Oliveira et al. (2000), a prioridade da planta é refazer sua área foliar com o objetivo de maximizar a interceptação de luz incidente. Esse processo ocorre até que a massa de forragem aumente e as folhas começam a se sobrepor e sombrear umas às outras. Nesse momento, a altura e a massa de forragem aumenta rapidamente, porém a massa de forragem disponível começa a apresentar proporções cada vez menores de folhas e maiores de colmos à medida que o período de rebrota aumenta (SILVA, 2005).

A percentagem de folhas, colmo e material morto foram influenciadas pelas doses de adubação nitrogenada e pela altura de corte $(P<0,001)$, sendo verificado efeito linear crescente para a proporção de folhas e colmos e efeito linear decrescente para a proporção de material morto (Figura 4) conforme aumento da adubação nitrogenada.

A resposta da adubação nitrogenada está de acordo com os resultados de Fagundes et al. (2011), de que o maior crescimento e desenvolvimento das plantas ocorre nas maiores doses de nitrogênio este efeito é observado no aumento dos primórdios foliares e aumento do número de folhas vivas emergentes com redução do material morto. Rezende et al. (2015) verificaram que a adubação nitrogenada aumentou a proporção de folhas/colmo além de alterar o tamanho das lâminas foliares em Jiggs e Tifton 85.

Figura 4. Composição estrutural com relação ao percentual de folhas, colmo e material morto na massa total da forragem de Jiggs, em função de doses de adubação nitrogenada.

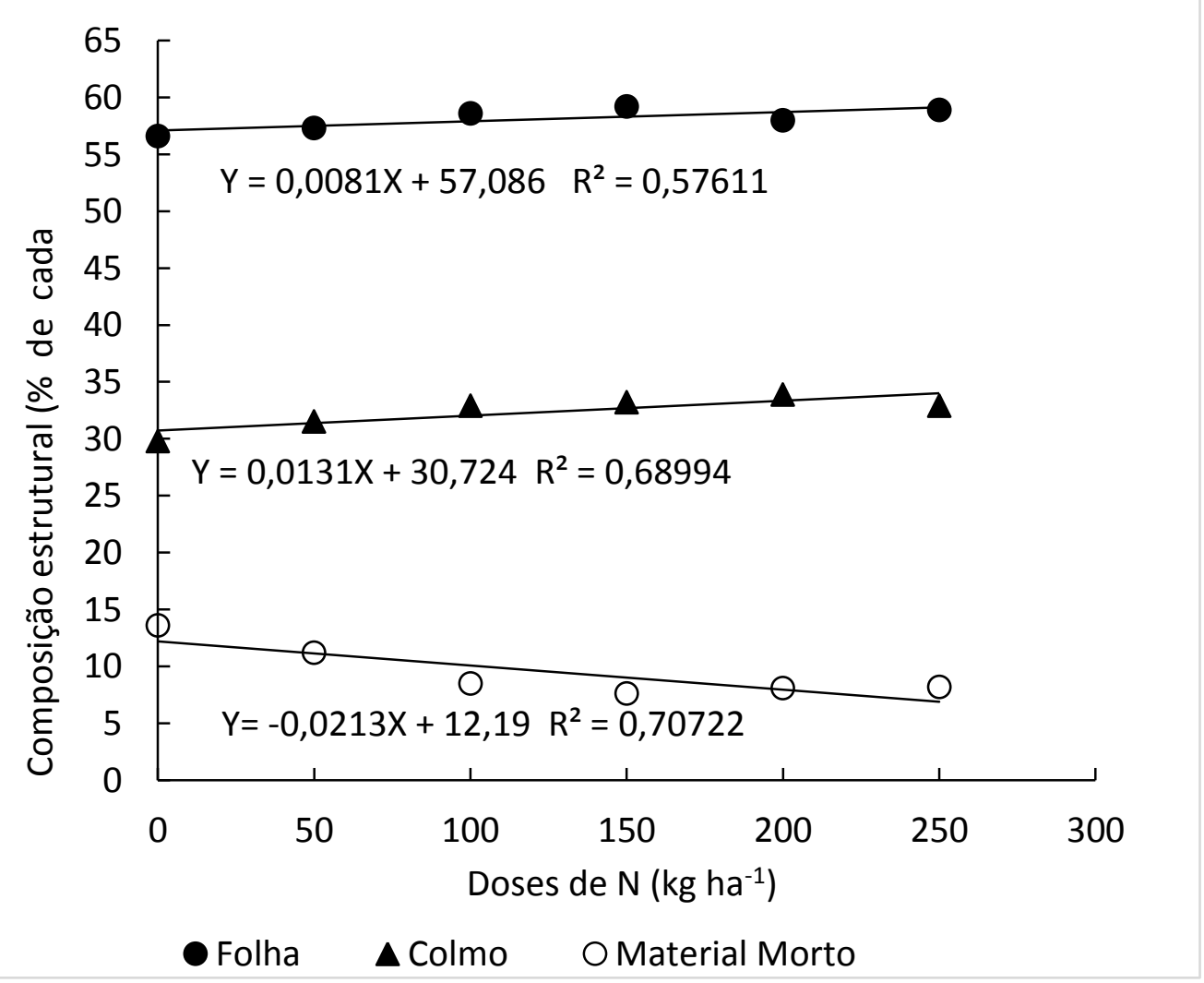


Houve efeito significativo $(P<0,05)$ das alturas de corte sobre os componentes estruturais da forragem. Na altura de corte a 7 $\mathrm{cm}$ houve maior concentração de folhas e menor concentração de colmos e material morto (Tabela 2). Pereira et al. (2012) inferiram que a área foliar decresce linearmente com o aumento da altura de corte $(30,40$ e $50 \mathrm{~cm})$ do capim tifton, e por outro lado, aumenta linearmente com a dose de nitrogênio.

Tabela 2. Percentagem dos componentes: folha, colmo e material morto na massa total da forragem de Jiggs em relação a alturas de corte.

\begin{tabular}{lcc}
\hline Componentes & \multicolumn{3}{c}{ Alturas de corte $(\mathrm{cm})$} \\
\cline { 2 - 3 } & $0 \mathrm{~cm}$ & $7 \mathrm{~cm}$ \\
\hline Folha (\%) & $53,3 \mathrm{~B}$ & $61,3 \mathrm{~A}$ \\
Colmo (\%) & $33,9 \mathrm{~A}$ & $31,8 \mathrm{~B}$ \\
Material Morto (\%) & $12,8 \mathrm{~A}$ & $6,9 \mathrm{~B}$ \\
\hline \multicolumn{2}{l}{ Médias seguidas por letras diferentes na linha diferem entre si $(\mathrm{P}<0,05)$ pelo teste de Tukey. }
\end{tabular}

Médias seguidas por letras diferentes na linha diferem entre si $(P<0,05)$ pelo teste de Tukey.

As características bromatológicas apresentadas pelas folhas são as mais desejáveis para a nutrição animal quando comparada às apresentadas pelos colmos. A adubação nitrogenada incrementou os teores de PB da forragem em ambas alturas de corte. Os teores de PB apresentaram comportamento linear crescente em resposta a adubação nitrogenada, entretanto foram observados teores de $\mathrm{PB}$ maiores no corte a $7 \mathrm{~cm}$ de altura variando os teores entre 13,9 a 20,4\% (Figura 4).
Os resultados obtidos foram superiores aos observados por Roecker et al. (2011), que quando aplicado $300 \mathrm{~kg}$ de $\mathrm{N} \mathrm{ha}{ }^{-1} \mathrm{em}$ pastagem de Jiggs obtiveram $17,1 \%$ de PB. Em pastagem de Tifton 85, Alvim et al. (1998), verificaram com $600 \mathrm{~kg} \mathrm{ha}^{-1}$ de $\mathrm{N}$ e altura de corte $7 \mathrm{~cm}$, teor de $21,7 \%$ de $\mathrm{PB}$, resultados parecidos com os obtidos nesta pesquisa.

Figura 4. Teor de proteína bruta (PB) na MS de acordo com as doses de adubação nitrogenada e alturas de corte da forragem de Jiggs.

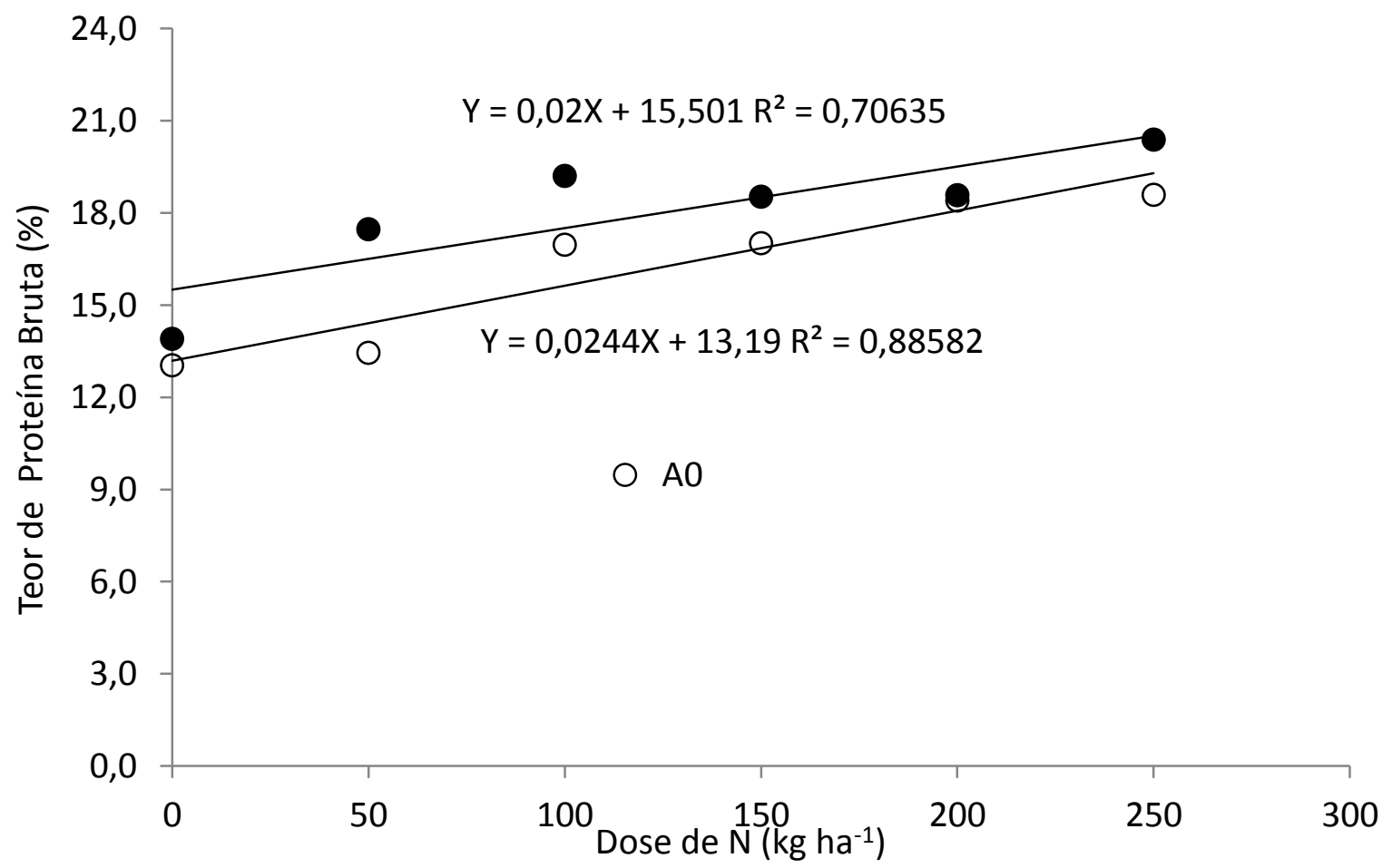

A0: Altura de corte a $0 \mathrm{~cm}$; A7: Altura de corte a $7 \mathrm{~cm}$; 
Observa-se que os valores encontrados para PB foram relativamente altos quando comparados a outros autores, Gonçalves et al. (2003) justifica que a forragem oriunda de tecidos mais novos, apresentam maior qualidade, o mesmo ocorrendo quando doses maiores de fertilizantes nitrogenados são aplicados, resposta conhecida quando se avalia os níveis de PB em função da adubação nitrogenada (MOREIRA et al., 2009). Segundo Carvalho (2011), o maior índice de área foliar residual assegura uma rápida recuperação inicial, através de uma interceptação luminosa eficiente e consequentemente maior qualidade do material ingerido pelo animal. A altura de corte a $7 \mathrm{~cm}$ proporcionou a forragem produção de maior quantidade de folhas jovens e consequentemente maior quantidade de PB na forragem produzida.

A quantidade de PB produzida por área é de fundamental importância na produção animal em sistemas intensivos de produção, principalmente quando é realizado o corte da forrageira para ser fornecida diretamente no cocho ou através do processo de fenação. Considerando o limite máximo inferior na produção da MS da forragem de Jiggs na altura de corte de 7 e $0 \mathrm{~cm}$ que foi de 6.387 e 5.221,74 kg MS ha ${ }^{-1}$, respectivamente, e multiplicando estes valores pelo teor máximo de $\mathrm{PB}$ obtido na dose de $250 \mathrm{~kg}$ de $\mathrm{N} \mathrm{ha}^{-1}$, que foram de $20,4 \mathrm{e}$ $18,6 \%$, para as alturas de 7 e $0 \mathrm{~cm}$, respectivamente, obteve-se produção por área de PB de $1.303,12 \mathrm{~kg}$ de PB ha ${ }^{-1}$ no corte a $7 \mathrm{~cm}$ de altura e de $971,74 \mathrm{~kg}$ de $\mathrm{PB} \mathrm{ha}{ }^{-1}$ no corte rente ao solo. Conforme o NRC (2001), para produção de $1 \mathrm{~kg}$ de leite com $4 \%$ de gordura são necessários $90 \mathrm{~g}$ de PB. Assim, o potencial destes dois manejos para a produção leiteira é de $14.479,11 \mathrm{~kg}$ de leite $\mathrm{ha}^{-1}$ no corte a $7 \mathrm{~cm}$ de altura versus $10.794,11 \mathrm{~kg}$ de leite ha ${ }^{-1}$ no corte rente ao solo, resultando numa diferença entre os manejos de alturas de corte de 3.685 litros de leite ha ${ }^{-1}$. Esta diferença representa um incremento na ordem de $34,11 \%$ da produção leiteira quando o corte da forrageira é realizado a $7 \mathrm{~cm}$ de altura e utilizada adubação nitrogenada para proporcionar incrementos na produção de MS e no teor de proteína bruta da forragem.

\section{Conclusões}

As maiores produções de MS por área, taxa de acúmulo de MS diária e teor de PB do Jiggs são alcançadas com cortes a $7 \mathrm{~cm}$ de altura e aplicação de adubação nitrogenada em cobertura.

A composição estrutura da forragem é positivamente afetada pelo aumento da quantidade de folhas verdes e redução do material morto do Jiggs no corte a $7 \mathrm{~cm}$ de altura e doses crescentes de $\mathrm{N}$.

$\mathrm{O}$ aumento na produção de matéria seca por área e de proteína bruta quando o Jiggs foi cortado a $7 \mathrm{~cm}$ de altura e recebeu $\mathrm{N}$ em cobertura poderá proporcionar incrementos significativos na produção animal por área, considerando que a maioria das propriedades realizam o corte desta forrageira rente ao solo.

\section{Referências}

ALVARES, C.A.; STAPE, J. L.; SENTELHAS, P. C.; GONÇALVES, J. L. M.; SPAROVEK, G. Köppen's climate classification map for Brazil. Meteorologische Zeitschrift, Stuttgart, v. 22, n. 6, p. 711-728, 2014. https://doi.org/10.1127/0941$\underline{\text { 2948/2013/0507 }}$

ALVIM, M. J.; XAVIER, D. F.; BOTREL; M. A.; MARTINS, C.E. Resposta do coast-cross (Cynodon dactylon(L.) Pers.) a diferentes doses de nitrogênio e intervalos de corte. Revista Brasileira de Zootecnia, Viçosa, v. 27, p. 833-840, 1998.

AMADO, T. J. C.; MIELNICZUK, J.; AITA, C. Recomendação de adubação nitrogenada para o milho no RS e SC adaptada ao uso de culturas de cobertura do solo, sob sistema plantio direto. Revista Brasileira de Ciência do Solo, Viçosa, v. 26, p. 241-248, 2002.

AOAC. Official methods of analysis. 15. ed. Gaithersburg, USA: Richmond, 1990. 1298p.

CARNEVALLI, R.A.; SILVA, S.C. Validação de técnicas experimentais para avaliação de características agronômicas e ecológicas de pastagens de Cynodon dactylon cv. Coastcross- 1 . Scientia Agricola, Piracicaba, v.56, n.2, p.489-499, $1999 . \quad$ https://doi.org/10.1590/S010390161999000200032

CARVALHO, M. S. S. Desempenho agronômico e análise de crescimento de capins do gênero Cynodon em resposta à frequência de corte. 2011. 96p. Dissertação (Mestrado) - Escola Superior de Agricultura Luiz de Queiroz, Universidade de São Paulo, Piracicaba, 2011. 
https://doi.org/10.11606/D.11.2011.tde21112011-144253

CQFS. Manual de Calagem e Adubação para os Estados do Rio Grande do Sul e de Santa Catarina. Porto Alegre: SBCS, 2016. 376p.

DORE, R. T. Comparing Bermuda grass and bahia grass cultivar sat different stage sofhar vest for dry matter yied and nutrient ontent. The Inter departmental Program of Animal and Dairy Sciences, v. 79, 2006.

EMBRAPA. Sistema brasileiro de classificação de solos. 3. ed. Brasília, 2013. 353p.

FAGUNDES, J.L.; FONSECA, D.M.; GOMIDE, J.A.; NASCIMENTO JUNIOR, D.; VITOR, C.M.T.; MORAIS, R.V.; MISTURA, C.; REIS.G.C.; MARTUSCELLO, J.A. Acúmulo de forragem em pastos de Brachiaria decumbens adubados com nitrogênio. Pesquisa Agropecuária Brasileira, Brasília, v.40, n.4, p.397-403, 2005. https://doi.org/10.1590/S0100-

\section{X2005000400012}

FAGUNDES, J. L.; MOREIRA, A.L.; FREITAS, A.W.P.; ZONTA, A.; HENRICHS, R.; ROCHA, F. C.; BACKES, A. A.; VIEIRA, J.S. Capacidade de suporte de pastagens de capim-tifton 85 adubado com nitrogênio manejadas em lotação contínua com ovinos. Revista Brasileira de Zootecnia, Viçosa, v.40, n.12, p.2651-2657, 2011.

FONSECA, D.M.; SANTOS, M.E.R.; MARTUSCELLO, J.A. Adubação de pastagens no Brasil: uma análise crítica. In: SIMPÓSIO SOBRE MANEJO ESTRATÉGICO DA PASTAGEM, 4., 2008, Viçosa, MG. Anais [...] Viçosa, MG: UFV, 2008. p.295-334.

GONÇALVES, G. D.; SANTOS, G. T.; JOBIM, C. C.; DAMASCENO, J.C.; ULYSSES, C.; BRANCO A. F. Determinação do consumo, digestibilidade e frações protéicas e de carboidratos do feno de Tifton 85 em diferentes idades de corte. Revista Brasileira de Zootecnia, Viçosa, v.32, p. 804-813, 2003.

MOREIRA, L. M.; MARTUSCILLO, J. A.; FONSECA, D. M.; MISTURA, C.; MORAIS, R.V; RIBEIRO JÚNIOR, J.I. Perfilhamento, acúmulo de forragem e composição bromatológica do capim-braquiaria adubado com nitrogênio. Revista Brasileira de Zootecnia, Viçosa, v. 38 p. 1675-1684, 2009.
NRC. Nutrient requeriments of dairy cattle. 7. ed. Washinton, 2001. 381p.

OLIVEIRA, M. A.; PEREIRA, O. G.; GOMIDE, J. A. Huaman, C.A.M.; Garcia, R.; Cecon, P. R. Análise de Crescimento do Capim-Bermuda 'Tifton 85' (Cynodon spp.). Revista Brasileira de Zootecnia, Viçosa, v.29, p.1930-1938, 2000.

PARSONS, A. J. The physiology of grass production under grazing. I. Characteristic of leaf and canopy photosynthesis of continuoulsly grazed swards. Journal of Applied Ecology, London, v.20, p.117-126, 1983. https://doi.org/10.2307/2403380

PEDREIRA, C. G. S.; MELLO, A. C. L.; OTANI, L. 20010 processo de produção de forragem em pastagem. In: SOCIEDADE BRASILEIRA DE ZOOTECNIA (Piracicaba, SP). A produção animal na visão dos brasileiros. Piracicaba: Fealq, 2001. p. 772-807.

PEREIRA, O. G.; ROVETTA, R.; RIBEIRO, K. G.; SANTOS, M. E. R.; FONSECA, D. M.; CECON, P. R. Crescimento do capim-tifton 85 sob doses de nitrogênio e alturas de corte. Revista Brasileira de Zootecnia, v.41, n.1, p.30-35, $2012 . \quad$ https://doi.org/10.1590/S1516$\underline{35982012000100005}$

REZENDE, A.V.; RABÊLO, F.H; RABELO, C.H.S.; LIMA, P. P.; BARBOSA, L. Á.; ABUD, M.C; SOUZA, F. R. C. Características estruturais, produtivas e bromatológicas dos capins Tifton 85 e Jiggs fertilizados com alguns macronutrientes. Semina, Londrina, v.36, n.3, p.1507-1518, 2015. https://doi.org/10.5433/1679-

0359.2015v36n3p1507

ROECKER, J.R.; GAI, V.F.; MOREIRA, G.C. Adubação nitrogenada em grama jiggs. Cultivando o Saber, Cascavel, v.4, n.3, p.140-147, 2011.

SILVA, A. C. F.; QUADROS, C. F. F.; TREVISAN, N. B. Martins, C.E.N; Bandinelli, D. G. Alternativa de manejo de pastagem hibernal: níveis de biomassa de lâmina foliar verde. Revista Brasileira de Zootecnia, Viçosa, v. 34, n. 2, 2011.

SILVA, S.C. Potencial das pastagens de Cynodon na pecuária de corte. In: VILELA, D. ; RESENDE, 
J.C. ; LIMA, J. Cynodon: forrageiras que estão revolucionando a pecuária brasileira. Juiz de Fora, 2005, p.177-189.

SILVA, V.J.; PEDREIRA, C.G.S.; SOLLENBERGER, L.E.; CARVALHO, M.S.S.; TONATO F.; BASTO, D.C. Seasonal herbage accumulation and nutritive value of irrigated 'tifton 85 ', jiggs, and vaquero bermuda grasses in response to harvest frequency. Crop Science, v.55, p.28862894, 2015.

https://doi.org/10.2135/cropsci2015.04.0225

VITOR, C.M.T.; FONSECA, D.M.; CÓSER, A.C.; MARTINS, C.E.; NASCIMENTO JÚNIOR, D.; RIBEIRO JÚNIOR, JI. Produção de matéria seca e valor nutritivo de pastagem de capim-elefante sob irrigação e adubação nitrogenada. Revista Brasileira de Zootecnia, Viçosa, v.38, n.3, p.435442, 2009.

VIANA, M.C.M.; FREIRE, F. M.; FERREIRA, J.J.; CANTARUTTI, R. B.; MASCARENHAS, M.H. T. Adubação nitrogenada na produção e composição química do capim-braquiária sob pastejo rotacionado. Revista Brasileira de Zootecnia, Viçosa, v.40, p.1497-1503, 2011.

ZEVIANI, W.M. Parametrizações interpretáveis em modelos não lineares. 2013. 146f. Tese (Doutorado em Estatística e Experimentação Agropecuária)- Universidade Federal de Lavras, Lavras, 2013. 